\title{
Kinerja pengelolaan arsip Kantor Pelayanan Utama Bea dan Cukai Tipe A Tanjung Priok
}

\author{
Kartini $^{1}$, Sukaesih ${ }^{2}$, Agung Budiono ${ }^{3}$ \\ 1Perpustakaan Pascasarjana Universitas Negeri Jakarta \\ Jl. Rawamangun Muka, Pulo Gadung, Jakarta Timur, 13220 \\ 2,3Program Studi Ilmu Perpustakaan, Universitas Padjadjaran \\ Jl. Raya Bandung - Sumedang Km. 21, Jatinangor, Sumedang, Jawa Barat, 45363 \\ E-mail: ${ }^{1}$ kartini14001@mail.unpad.ac.id , ${ }^{2}$ sukaesih@unpad.ac.id , ${ }^{3}$ agung.budiono@unpad.ac.id
}

Received: April 2019; Accepted: December 2019; Published: December 2019

\begin{abstract}
The dynamic records management of goods import notification documents is an essential activity in storing data on goods entering Indonesia. The Main Service Office for Customs and Excise Type A Tanjung Priok as a government agency is obliged to record incoming goods as trade data. This study aimed to determine the dynamic records management of imported goods notification (PIB) documents on customs activities for the success of dwelling time at the Main Service Office for Customs and Excise Type A Tanjung Priok. The research method used a case study through a qualitative approach. Data collection techniques used were observation, interviews, and document study. The results showed the process of recording imported goods document notifications through the process of creating and receiving import documents began from the delivery of imported goods document notification (PIB) to the Customs Office. Submitting of the notifications was through the Electronic Data Exchange (PDE) system to the determination of the document path for 4 minutes. The organization process of notification documents for imported goods goes through 5 stages, namely, distribution of documents, the process of completing customs administration of imported goods documents, storing the processed documents, rediscovering documents, and maintaining imported goods documents. The process of dissemination at the Customs and Excise agency itself is inseparable from a system called Customs-Excise Integrated System and Automation (CEISA). The system is an integrated system of all Directorate General Customs and Excise services to all public service users. Their can access this system without limited space and place.
\end{abstract}

Keywords: Dynamic archive management; Goods import notification documents; Customs

\begin{abstract}
Abstrak
Pengelolaan arsip dinamis dokumen pemberitahuan impor barang merupakan kegiatan penting dalam menyimpan data barang masuk ke Indonesia. Kantor Pelayanan Utama Bea dan Cukai Tipe A Tanjung Priok sebagai lembaga pemerintah berkewajiban mencatat barang masuk sebagai data perdagangan. Penelitian ini bertujuan mengetahui pengelolaan arsip dinamis dokumen pemberitahuan impor barang (PIB) pada kegiatan kepabeanan untuk keberhasilan dwelling time di Kantor Pelayanan Utama Bea dan Cukai Tipe A Tanjung Priok. Metode penelitian yang digunakan ialah studi kasus melalui pendekatan kualitatif. Teknik pengumpulan data melalui observasi, wawancara dan studi dokumen. Hasil penelitian menunjukkan bahwa proses recording dokumen pemberitahuan impor barang melalui proses penciptaan dan penerimaan dokumen impor dari penyampaian dokumen pemberitahuan impor barang (PIB) ke Kantor Pabean yang disampaikan melalui sistem Pertukaran Data Elektronik (PDE) hingga penetapan jalur dokumen selama 4 menit. Proses organization dokumen pemberitahuan impor barang melalui 5 tahapan yaitu, pendistribusian dokumen, proses penyelesaian administrasi kepabeanan dokumen impor, penyimpanan dokumen yang telah selesai diproses, penemuan kembali dokumen, dan pemeliharaan dokumen impor. Proses dissemination pada instansi Bea dan Cukai menggunakan sistem bernama Customs-Excise Intergrated System and Automation (CEISA), sistem integrasi seluruh layanan Direktorat Jenderal Bea dan Cukai kepada semua pengguna jasa yang bersifat publik sehingga semua pengguna jasa sebagai user dapat mengakses sistem CEISA tanpa terbatasi ruang dan tempat.
\end{abstract}

Kata Kunci: Pengelolaan arsip dinamis; Dokumen pemberitahuan impor barang; Kepabeanan 


\section{PENDAHULUAN}

Kantor Pelayanan Utama Bea dan Cukai Tipe A Tanjung Priok memiliki tanggung jawab pengawasan mengenai barang impor ke kawasan pabean. Pada prinsipnya barang impor yang masuk ke kawasan pabean dapat dikeluarkan sebagai barang impor bila telah melalui prosedur sesuai peraturan di pabean. Hal ini terkait fungsi utama bea dan cukai yaitu sebagai instansi yang menghimpun penerimaan negara (revenue collection). Pelabuhan Tanjung Priok merupakan menerima impor barang di seluruh Indonesia dengan penerimaan dokumen impor sebanyak 500.000-600.000 setiap tahunnya (Kantor Pelayanan Utama Bea dan Cukai Tipe A Tanjung Priok, 2018). Hal ini terjadi karena $70 \%$ penerimaan barang impor berpusat di sini. Oleh karena itu, lembaga ini memegang kendali penuh memeriksa semua barang impor. Pihak importir harus mengajukan dokumen impor atau Pemberitahuan Impor Barang (PIB) kepada Bea dan Cukai atas barang impor. PIB adalah suatu dokumen pemberitahuan kepada bea dan cukai atas barang impor, yang berisi perincian berupa jumlah pajak dan bea masuk yang harus dibayarkan atas barang impor.

Berdasarkan penerimaan dokumen yang semakin meningkat setiap tahun, maka perlu dilakukan pengelolaan arsip. Hal ini dilakukan agar dokumen peneriman impor barang dapat dikelola baik dan sesuai prosedur, dan sebagai jejak rekaman aktivitas organisasi tersebut (Chairisnaeni, Rusmana \& Komariah, 2014). Berikut ini adalah data mengenai jumlah dokumen PIB yang diterima petugas penerimaan dokumen.

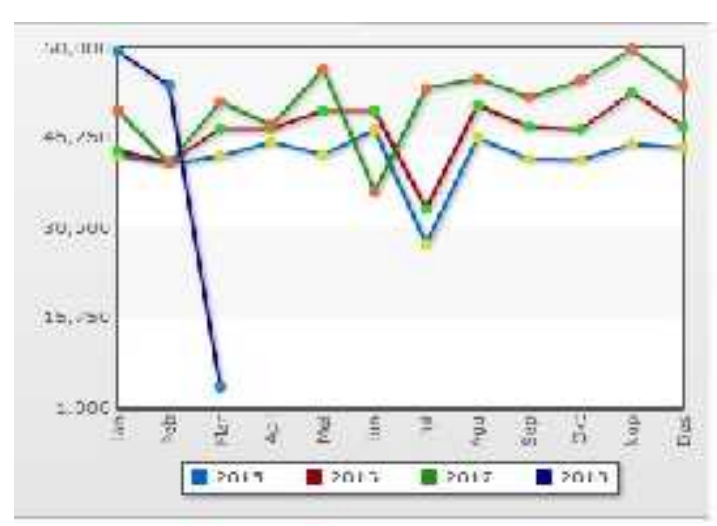

Gambar 1. Penerimaan dokumen pemberitahuan impor barang pada aplikasi SIAP

Sumber: Kantor Pelayanan Utama Bea dan Cukai Tipe A Tanjung Priok, 2018

Berdasarkan gambar tersebut, pada 2015, dokumen pemberitahuan impor barang yang diterima sejumlah 502.827. Adapun pada 2016 sebanyak 553.980, lalu di tahun selanjutnya 2017 mengalami peningkatan yang cukup signifikan yakni menerima dokumen sebanyak 609.887 (Kantor Pelayanan Utama Bea dan Cukai Tipe A Tanjung Priok, 2018). Jumlah dokumen pemberitahuan impor barang setiap tahun dapat dilihat dalam aplikasi internal bernama Sistem Informasi dan Administrasi Pelayanan (SIAP) dan aplikasi Customs-Excise Intergrated System and Automation (CEISA). Kedua aplikasi ini merupakan sistem teknologi informasi kepabeanan DJBC. Para pegawai dapat melihat semua informasi mengenai kegiatan kantor dan pengumumam penting lainnya terkait kegiatan kepabeanan. Hal ini sesuai pendapat Kusnandar and Yusup (2015) yang menyatakan, "Penerapan teknologi informasi dan komunikasi lebih terasa manfaatnya terutama dalam hal pemberdayaan arsip dalam bentuk aktivitas penelusuran kembali arsip." Kegiatan pengajuan dokumen PIB dilakukan importir atau pihak yang 
sedang menjabat. Pada umumnya, importir menguasakan pengurusan kepada Pengusaha Pengurusan Jasa Kepabeanan (PPJK), menggunakan program aplikasi modul PIB importir/PPJK secara lengkap dan benar.

Kegiatan arsip merupakan pondasi berdirinya suatu lembaga. Maka, beberapa penelitian mengkaji mengenai kegiatan arsip di perkantoran, dianalisis dari proses arsip, arsiparis dan secara kelembagaan. Adapun penelitian terdahulu yang mengkaji kegiatan arsip dapat menjadi pembanding dengan penelitian yang penulis teliti, di antaranya sebagai berikut.

Pertama, penelitian Nurulita (2015), yang dilakukan di Kementerian Pekerjaan Umum Republik Indonesia. Kegiatan pengelolaan arsip di lembaga ini belum dilakukan dengan baik dan masih memiliki kendala.

“Sistem pengelolaan arsip dinamis pada administrasi perkantoran di Kementerian Pekerjaan Umum Republik Indonesia pada aspek penciptaan dan penerimaan arsip, penyimpanan, pemeliharaan, dan penyusutan. Perlengkapan arsip dinamis cukup baik dan masih layak digunakan. Pengelolaan arsip dinamis, ada 5 kendala yang dihadapi oleh administrasi perkantoran di Biro Umum yaitu anggaran dana, fasilitas penunjang pengelolaan arsip dinamis, sistem pengamanan, kurang pegawai dalam bidang kearsipan, dan kegiatan dalam mengoptimalkan Sumber Daya Manusia (SDM). Dasar hukum pengelolaan arsip dinamis administrasi perkantoran di Biro Umum berupa kebijakan, dan Standar Operasional Prosedur (SOP) mengenai pengelolaan arsip dinamis" (Nurulita, 2015).
Adapun penelitian kedua dari Nurrahman (2016), yang dilakukan di bagian kearsipan Sekretariat Jenderal Dewan Perwakilan Daerah Republik Indonesia. Penelitian ini menceritakan bahwa pengelolaan arsip di lembaga ini masih belum berjalan dengan baik karena kekurangan staf atau arsiparis dan fasilitas ruang arsip. Berdasarkan kedua penelitian terdahulu di atas, terlihat bahwa SDM menentukan dalam kelancaran kegiatan arsip di suatu lembaga. Staf atau arsiparis di lembaga tersebut harus dapat menganalisis dokumen yang sesuai untuk diarsipkan atau harus jeli melihat kualitas dokumen. Selain itu, staf atau arsiparis harus aktif berkomunikasi dengan berbagai bidang dalam distribusi dokumen agar sampai ke unit arsip.

Adapun dokumen PIB merupakan arsip dinamis yang dipakai pada kegiatan impor barang, yang akan diterima Bagian Penerimaan Dokumen (Pendok) dalam bentuk hardcopy. Proses pelayanan dan penerimaan hardcopy dokumen PIB dan dokumen pelengkap pabean lainnya pada dokumen PIB jalur merah atau jalur kuning dimulai sejak diterimanya hardcopy PIB beserta dokumen pelengkap pabean oleh Kantor Pelayanan Utama Bea dan Cukai Tipe A Tanjung Priok dari importir sampai penerbitan Bukti Penerimaan Berkas PIB (BPBP) hingga penyerahan hardcopy dokumen PIB kepada staf Pejabat Fungsional Pemeriksa Dokumen (PFPD).

Unit terkait Pelayanan Penerimaan Dokumen PIB jalur merah atau jalur kuning adalah Seksi Pabean dan Cukai I pada Bidang Pelayanan Pabean dan Cukai IV. Pelaksanaan Pelayanan Penerimaan Dokumen PIB jalur merah atau jalur kuning adalah petugas penerima dokumen secara struktural berada di bawah Seksi Pabean dan Cukai I pada 
Bidang Pelayanan Pabean dan Cukai IV.

Sunarmin, Utami, and Yulianita (2019) menjelaskan,

"Pada importasi yang ditetapkan jalur merah, dilakukan pemeriksaan fisik barang dan penelitian dokumen impor kemudian diterbitkan SPPB (Surat Persetujuan Pengeluaran Barang), pada jalur kuning hanya dilakukan penelitian dokumen dan kemudian dapat diterbitkan SPPB tanpa dilakukan pemeriksaan fisik, sedangkan pada jalur hijau dapat terbit SPPB tanpa dilakukan pemeriksaan barang dan penelitian dokumen dilakukan setelahnya. Sedangkan untuk jalur MITA memungkinkan proses pengeluaran barang impor tanpa dilakukan pemeriksaan fisik dan penelitian dokumen."

Berdasarkan gambar 2 (daftar gambar), di tahun 2006-2007 proses penerimaan dan pengelolaan dokumen PIB masih dilakukan secara manual, sehingga prosedur kerja yang memakan waktu. Sistem aplikasi belum terintegrasi dengan internet. Para importir biasanya menyerahkan hardcopy lengkap dokumen PIB secara langsung kepada Kantor Kepabeanan, dan disertai data yang sudah disimpan dalam disket. Kemudian data tersebut dimasukkan pada aplikasi Kepabeanan. Hal ini hanya dapat diakses pegawai Bea dan Cukai saja sehingga proses pengeluaran barang impor memakan waktu yang akan berakibat pada biaya inap barang impor di pelabuhan. Apabila terdapat masalah pada data dalam disket, seperti data yang tidak dapat ditampilkan maka importir harus kembali lagi ke Kantor Kepabeanan untuk memperbaikinya (J. Fourina, wawancara, March 08, 2018). Oleh karena itu, sekarang ini proses penerimaan dokumen PIB dilakukan bagian penerimaan dokumen sampai bagian batching yang bertugas mengarsipkan PIB untuk disimpan pada gudang arsip pusat di Marunda. Bagian batching memiliki tugas sebagai bagian pengarsipan dokumen PIB yang sudah selesai diteliti dan diperiksa PFPD.

Staff batching akan mengambil PIB yang kemudian diarsipkan menggunakan aplikasi internal SIAP yang di dalamnya terdapat aplikasi pengarsipan. Peneliti mengkaji penelitian ini menggunakan teori dokumentasi dari Federation Internationale de Documentation (FID) (1951), "Documentation is organization, storage, retrieval, dissemination, evaluation of information recorded in the field of science, technology, social sciences and humanities" (Nugrohoadhi, 2015). Sesuai rujukan ini, dokumentasi dimulai dari penyusunan hingga penyebaran kembali dokumen pada pengguna. Peneliti mengadaptasi dan memodifikasi teori tersebut berdasarkan sumber data penelitian yang terdiri dari recording, organization, dan dissemination. Dengan demikian, peneliti tertarik untuk mengkaji lebih mendalam mengenai proses recording, organizationing, dan dissemination pada pengelolaan arsip dinamis dokumen pemberitahuan impor barang untuk keberhasilan dwelling time di Kantor Pelayanan Utama Bea dan Cukai Tipe A Tanjung Priok.

\section{METODE PENELITIAN}

Peneliti menggunakan metode penelitian studi kasus melalui pendekatan kualitatif untuk membantu menganalisis kegiatan pengelolaan arsip di lembaga penelitian. Metode penelitian kualitatif merupakan penelitian yang dilakukan pada obyek yang alamiah. Sugiyono (2011) dalam Ramadhani and Subekti 
(2018) mengatakan bahwa peneliti memiliki peran merancang obyek alami sesuai hasil temuan di lapangan. Peneliti menggunakan pendekatan kualitatif bertujuan untuk memaparkan secara jelas mengenai pengelolaan dokumen pemberitahuan impor barang dalam kepabeanan di Kantor Pelayan Utama Bea dan Cukai Tipe A Tanjung Priok. Dokumen yang diteliti ialah arsip dinamis, arsip yang masih secara aktif digunakan oleh staf suatu lembaga. Arsip mengenai impor barang merupakan arsip yang menjadi ciri khas dilakukan di Kantor Pelayan Utama Bea dan Cukai Tipe A Tanjung Priok.

Berdasarkan metode penelitian studi kasus, fenomena yang unik di masyarakat dapat dianalisis menggunakan pertanyaan bagaimana (how) dan mengapa (why). Peneliti melalui studi kasus, memiliki peluang mengontrol fenomena yang diteliti dan fokus membahas terhadap pertanyaan penelitian yang diajukan (Darono, Nugroho, \& Najib, 2013). Peneliti harus memahami permasalahan secara mendalam mengenai kegiatan pengelolaan dokumen pemberitahuan impor barang serta mendapatkan kepercayaan dari informan dengan memosisikan peneliti adalah pegawai yang mengalami secara langsung kegiatan pengelolaan dokumen PIB.

Subjek penelitian diambil dari 6 orang yang terdiri dari, petugas penerimaan dokumen, koordinator pejabat fungsional pemeriksa dokumen, pejabat fungsional pemeriksa dokumen, staf kepatuhan internal, dan koordinator batching yang terlibat langsung dalam proses pengelolaan dokumen pemberitahuan impor barang. Peneliti memilih subjek penelitian berdasarkan teknik purposive sampling, yakni pemilihan narasumber sesuai kriteria dan pertimbangan (Ramadhani, \& Subekti, 2018). Adapun objek penelitian adalah pengelolaan arsip dinamis dokumen pemberitahuan impor barang pada kegiatan kepabeanan.

Wardiana, Khadijah, and Rukmana (2018) mengatakan bahwa,

“Peneliti dapat menggunakan semua sumber dan metode pengumpulan data jika metode yang digunakannya dikuasai peneliti. Selain itu, peneliti harus mengerti apa yang dikatakan narasumber, apa yang mereka lihat, apa yang mereka hasilkan apakah dokumen dan rekaan lainnya."

Teknik pengumpulan data dilakukan menggunakan observasi, wawancara, dan studi pustaka. Peneliti dalam kegiatan observasi, ikut aktif membantu staf atau arsiparis dalam mengolah dokumen barang impor. Peneliti pun mewawancarai staf atau arsiparis yang berkaitan dengan pengolahan dokumen barang impor, dan mencari rujukan yang berkaitan dengan hal ini.

Ketika menganalisis data hasil temuan di lapangan, peneliti melakukan reduksi data, penyajian data, penarikan simpulan dan verifikasi. Kegiatan reduksi data, ialah merangkum data lapangan. Pada saat pengumpulan data di lapangan, peneliti mengelompokkan data, memilahmilah data mana yang memiliki hal yang penting, cocok dengan tujuan penelitian peneliti dari sejauh data yang diperoleh. Peneliti menandai data yang penting untuk diolah lebih lanjut.

Kegiatan penyajian data, ialah penguraian data menggunakan beberapa bentuk penyajian data, misal grafik, tabel atau matriks. Sesuai data yang diperoleh, peneliti menunangkan data ke dalam 
bentuk rancangan pola. Hal ini untuk menggambarkan keseluruhan data terutama mengenai proses yang diteliti, seperti membuat alur penerimaan dokumen PIB. Terakhir, kegiatan penarikan kesimpulan dan verifikasi

\section{HASIL DAN PEMBAHASAN}

Sesuai Peraturan Menteri Keuangan Nomor 68/PMK.01/2007 tanggal 27 Juni 2007, disebutkan bahwa, "Kantor Pelayanan Utama Bea Cukai Tanjung Priok yang berkedudukan di Pelabuhan Tanjung Priok Jakarta Utara mempunyai tugas melaksanakan pelayanan dan pengawasan, penelitian atas keberatan serta audit di bidang kepabeanan dan cukai dalam daerah wewenangnya berdasarkan peraturan perundangundangan yang berlaku"(Direktorat Jenderal Bea dan Cukai KPU Bea dan Cukai Tipe A Tanjung Priok, 2019).

Kantor Pelayanan Utama Bea Cukai Tanjung Priok menjadi lembaga penerima barang impor pertama. Importir yang akan mengambil barang harus mengikuti beberapa proses yang telah ditetapkan lembaga ini, melalui prosesnya sesuai temuan data di lapangan pada tabel 1 (daftar tabel).

Kegiatan pertama, yakni proses recording. Setiap dokumen dari importir mengalami proses penciptaan dan penerimaan. Para importir harus melaksanaan prosedur dalam pindah tangan barang impor untuk membawa barang impor. Salah satunya importir melengkapi dokumen Penyerahan Impor Barang (PIB) sesuai kelengkapan dokumen pabean pada gambar 3(daftar gambar).

Aktivitas penciptaan dokumen dilakukan oleh bagian penerimaan dokumen, tempat penerimaan dokumen terpisah dari kantor utama yang dapat ditempuh waktu 10 menit. Hal ini dilakukan untuk memberikan kemudahan kepada importir dalam pengurusan dokumen barang impor agar langsung diterima di pelabuhan. Setiap barang impor yang datang, maka petugas akan memproses penyampaian dokumen PIB ke Kantor Pabean berupa data elektronik melalui sistem Pertukaran Data Elektronik (PDE) Kepabeanan.

Staf loket menerima dokumen impor yang masuk setelah melalui beberapa tahap, di antaranya pengisian PIB, pembayaran, pengiriman data PIB, pihak bank integrasi dengan kantor kepabean, dan penerimaan kelengkapan dokumen tercetak. Importir mengisi data impor barang ke dalam aplikasi PIB dan melakukan pembayaran bea masuk. Ketiga, importir mengirim data PIB melalui portal INSW. Keempat, bank devisa persepsi/pos persepsi mengirim credit advice secara elektronik ke SKP berupa data PIB. Dokumen tercetak akan diterima staf loket untuk diperiksa kelengkapan dokumen dan memberikan bukti tanda terima dokumen.

Penerimaan dan pemeriksaan dokumen dilakukan melalui 3 (tiga) tahapan, yaitu pemeriksaan kelengkapan dokumen oleh staf loket penerimaan dokumen, perekaman data pada aplikasi SIAP, dan pemeriksaan lebih mendalam kelengkapan dokumen pelengkapan kepabeanan. Staf loket menerima dokumen untuk dilakukan pemeriksaan kelengkapan dokumen seperti surat kuasa importir kepada PPJK, surat tugas beserta fotokopi, dokumen pembayaran/ jaminan: bukti penerimaan negara, kode billing, SKB PPN/PPH, customs bond, L/C, voice dan/atau Packing List, ill of Landing. Adapun dokumen pelengkap cukai, 
antara lain CK 1a, CK 5 lembar-3, asuransi, sertificate of orgin, dokumen atau surat keputusan/ijin lainnya, seperti: izin karantina, BPOM, perdagangan, laporan surveyor, dan izin instansi terkait lainnya, Skep KPM dan Skep Fasilitas lainnya. Dokumen yang sudah sesuai dengan form checklist kelengkapan dokumen di atas, maka akan diberikan tanda terima. Setelah itu, staf akan memeriksa kelengkapan dokumen melalui proses perekaman dan pencetakan Bukti Penerimaan Berkas PIB (BPBP) pada aplikasi CEISA.

Aplikasi ini dalam penerimaan dokumen impor menetapkan jalur pengeluaran barang impor. Pada dasarnya perlakuan dan proses pemeriksaan dokumen merah, kuning, dan hijau akan tetap sama, namun harus sesuai peraturan yang berlaku. Pada dokumen jalur merah, dokumen barang impor diperiksa secara fisik lalu diterbitkannya SPPB. Dokumen jalur merah merupakan barang yang termasuk dalam kategori high risk. Adapun dalam dokumen jalur kuning, tidak dilakukan pemeriksaan fisik tetapi dilakukan penelitian dokumen sebelum penerbitan SPPB. Pemeriksaan fisik barang pada dokumen jalur kuning akan dilakukan jika hanya diperlukan. Selain itu, dokumen jalur hijau pun tidak dilakukan pemeriksaan fisik namun hanya penelitian dokumen setelah penerbitan SPPB. Hal ini dilakukan karena dokumen jalur hijau merupakan barang impor yang termasuk dalam kategori low risk.

Kegiatan proses organization pada dokumen impor barang berfokus pada kegiatan pendistribusian dokumen dari bagian penerimaan dokumen ke PFPD. Dokumen yang telah selesai diproses, akan dipergunakan kembali dokumen dan dilakukan pemeliharaan dokumen impor oleh KPU Bea Cukai Tanjung Priok. Proses pendistribusian dokumen dilakukan staf penerimaan dokumen secara bergantian. Tahap selanjutnya mengantarkan dokumen impor yang sudah selesai dalam proses perekaman, dan pemeriksaan kelengkapan dokumen pelengkap kepabeanan setiap 3 jam sekali, lalu diserahkan kepada staff PFPD.

Staf di bagian penerimaan dokumen melakukan 8 kali pengiriman yang mana dalam sekali pengiriman, dokumen yang dilakukan distribusi berkisar 10-20 dokumen. Dokumen yang diterima staf PFPD akan langsung dilakukan distribusi kepada PFPD berdasarkan nama yang sudah tertera pada dokumen impor. Sistem aplikasi SIAP akan secara otomatis menentukan nama PFPD yang memeriksa dokumen impor.

Staf PFPD akan langsung memproses dokumen impor sesuai proses administrasi kepabeanan. Adapun importir harus melengkapi dokumen saat pengajuan PIB mulai dari dokumen,

"Voice, packing List, B/L, polis asuransi, surat keputusan pemberian fasilitas/master list, Surat Keputusan Bebas Pajak dalam rangka impor (SKB), Surat Setoran Pabean Cukai dan Pajak (SSPCP), Angka Pengenal Impor (API), NPWP, Surat izin PPJK, surat tanda terima jaminan, perizinan dari instansi terkait lainnya. Dokumen impor yang diterima PFPD adalah dokumen yang mendapatkan penetapan jalur hijau, jalur kuning dan jalur merah. Dokumen diteliti lebih lanjut bertujuan untuk meyakinkan bahwa importir telah memberitahukan mengenai nilai pabean dan tarif sesuai dengan aturan 
yang berlaku"(Sunarmin, Utami, \& Yulianita, 2019).

Pada saat dokumen diteliti oleh staf PFPD, kadangkala para importir melakukan perubahan data. Biasanya terdapat kekeliruan data pemberitahuan pabean pada dokumen yang telah diserahkan. Selanjutnya, PFPD memberikan batas waktu kepada semua PIB selama 30 hari dalam proses penyelesaiannya. Namun, bea dan cukai memberikan kebijakan saldo nol untuk PIB merah/kuning yang harus diserahkan pada hari itu, dan selesai hari itu juga. Hal ini dilakukan untuk meningkatkan kelancaran arus barang.

Kegiatan impor barang yang masuk ke kawasan pabean erat kaitannya dengan dwelling time yakni,

"Waktu rata-rata yang dibutuhkan oleh satu kontainer atau paket kiriman mulai dari bongkar sampai dengan keluar pelabuhan/bandara (gate-out). Semakin tinggi persentase pemeriksaan fisik maka dapat dipastikan semakin tinggi pula angka dwelling Time yang dibutuhkan" (Sunarmin et al., 2019).

Bea cukai merupakan instansi yang memegang peranan penting dalam terjadinya dwelling time. Hal ini memengaruhi beberapa hal.

"Pertama pre custome clereance, tahap sebelum, saat, dan sesudah pemberitahuan kedatangan sarana pengangkut laut/udara, penyerahan manifest yang dilakukan oleh agen pelayaran/penerbangan, kemudian dilanjutkan dengan penyampaian pemberitahuan impor ke Bea dan Cukai. Kedua, customes clereance, tahap pemeriksaan yang terdiri dari pemeriksaan semua dokumen yang telah selesai dan pemeriksaan fisik barang kemudian terhadap barang tersebut dikeluarkan dari tempat penimbunan dan diterbitkan Surat Persetujuan Pengeluaran Barang (SPPB) oleh Bea dan Cukai. Ketiga, post custome clereance, tahap setelah Surat Persetujuan Pengeluaran Barang (SPPB) diterbitkan oleh Bea dan Cukai sampai dengan proses pengeluaran barang dari Tempat Penimbunan Sementara (TPS)" (Sunarmin, Utami, \& Yulianita, 2019).

Ketiga hal di atas sebagai upaya untuk mempertahankan dwelling time dengan memberlakukan pelayanan 24/7 Bea Cukai. Salah satu narasumber menjelaskan,

"Saat ini, Bea Cukai menerapkan sistem piket dan shift dalam pelayanan 24/7. Berdasarkan data, maksimal jam 12 malam permintaan pelayanan dari pengguna jasa sudah jarang. Apabila memang permintaan pelayanan sudah benar-benar 24 jam bergulir, bea cukai siap mengubah pola kerja menjadi shift sepenuhnya 24/7. Program layanan 24/7 Pelabuhan Tanjung Priok tidak akan berjalan maksimal jika tanpa ada dukungan dari hulu ke hilir, sehingga butuh kerjasama semua pihak untuk keberlangsungan layanan 24/7, jangan sampai $24 / 7$ hanya menjadi retorika semata" (Syafe'I, wawancara, March 1, 2018).

Perlu diketahui, Pelayanan di Bea Cukai Tanjung Priok terdapat on the spot seperti penyerahan dokumen, dan request seperti pemeriksaan fisik malam hari. KPU Bea Cukai Tanjung Priok ketika mempertahankan dwelling time menetapkan Indikator Kinerja Utama (IKU) untuk waktu penyelesain dokumen. Setelah dokumen PIB sudah selesai 
diperiksa PFPD, maka staf batching akan mengambil PIB tersebut kemudian mengarsipkan menggunakan aplikasi internal SIAP. Pengarsipan dilakukan sesuai nomor dokumen fisik yang dimasukkan ke dalam box arsip, diurut berdasarkan nomor batch. Setiap box terdapat 3 batch yang berisi 15 sampai 20 dokumen, atau tinggi dokumen $6,5 \mathrm{~cm}$ yang disimpan pada 1 box. Jika dokumen sudah disimpan, dokumen tersebut akan dikirim ke gudang arsip pusat di Marunda untuk disimpan. Namun, jika terdapat permintaan terhadap dokumen tersebut, maka dapat dilakukan peminjaman dokumen yang sebelumnya diperiksa terlebih dahulu melalui aplikasi SIAP.

Dokumen impor kadang kala dipinjam oleh instansi lain, misalnya seperti Komisi Pemberantasan Korupsi (KPK). Dokumen yang dipinjamkan secara eksternal, maka pihak peminjam harus mengajukan nota dinas yang ditujukan langsung kepada Kepala Direktorat Jenderal Bea dan Cukai. Setelah peminjam mendapatkan izin, maka surat diteruskan kepada kepala kantor yang bersangkutan untuk ditujukan langsung kepada bidang yang dituju, yaitu bidang kepatuhan internal yang meneruskan kembali suratnya kepada bidang PPC IV lalu ditujukan kembali ke Seksi PC II. Tahap terakhir, staf batching akan memproses surat untuk mencari dokumen melalui aplikasi SIAP.

Staf batching pun menangani kegiatan perawatan arsip. Namun, perawatan dan pemusnahan arsip secara teknis dilakukan pihak luar yang teha bekerja sama dengan KPU Bea dan Cukai Tanjung Priok. Narasumber menyatakan,

"Untuk perawatan arsip ruangan arsip yang ada di Marunda sudah dilengkapi anti lembab, anti rayap, dan anti api. Selain itu sesuai dengan Pedoman Kearsipan di Lingkungan Direktorat Jenderal Bea dan Cukai juga terdapat Pemeliharaan dan Pengamanan Fisik, dengan cara: 1) menghindari arsip dari sinar matahari/lampu penerangan secara langsung, untuk mencegah kertas menjadi kering dan rapuh; 2) mengusahakan tempat penyimpanan (rak/lemari arsip) terbuat dari metal; 3) membuka ruangan tempat penyimpanan arsip setiap dua minggu sekali untuk menjaga kelembaban udara di dalamnya, terutama ruangan yang tidak memiliki pengatur suhu; 4) melakukan penyedotan debu dalam ruangan penyimpanan arsip dengan membuka tutup dus arsip terlebih dahulu sekurang-kurangnya sekali dalam tiga bulan" (Yuyun, wawancara, March 5, 2018).

Arsip di KPU Bea dan Cukai Tanjung Priok ditempatkan pada 4 gudang. Gudang arsip untuk dokumen merah/kuning terdapat pada 2 gudang, sedangkan dokumen impor hijau terdapat pada 2 gedung lainnya. Selain itu, perawatan dokumen arsip terdiri dari pemeliharaan lingkungan dan fasilitas arsip inaktif dan penataan rak arsip. Pertama, pemeliharaan lingkungan dan fasilitas arsip inaktif berisi ruang arsip di mana gedung atau ruang arsip terhindar dari debu, kotor dan asap sehingga ruangan menggunakan filter untuk menyaring udara. Selain itu, ruang penyimpanan arsip merupakan ruang tersendiri dan tertutup agar aman, efisiensi kerja, dan terjaga kebersihannya. Adapun rak arsip yang digunakan memperhatikan segi kemanan dan daya 
tahan, menggunakan rak berbahan metal. Bahan ini lebih bagus dibandingkan kayu karena tidak mudah terbakar dan tahan lama. Bentuk rak bahan metal yang digunakan ada dua, rak statis dan rak bergerak. Rak statis seperti lemari dinding, filling cabinet, dan lemari. Rak bergerak ialah rak yang memiliki roda untuk memudahkan pemindahan arsip.

Pada proses disseminating, ialah proses penyebaran informasi mengenai impor barang kepada masyarakat. Hal ini dilakukan menggunakan CEISA, sebagai sistem informasi pelayanan pengguna jasa dalam pelayanan dokumen impor barang. Sistem ini menjadi aplikasi tumpuan Bea dan Cukai untuk menunjang tugas pokok dan fungsi Direktorat Jenderal Bea dan Cukai. CEISA berfungsi dalam pelaksanaan administrasi, pelayanan, dan pengawasan. Sistem CEISA dikembangkan pada 2011 oleh Pusat Teknologi Informasi dan Komunikasi Direktorat Jenderal Bea dan Cukai. Sistem ini memiliki beberapa prinsip. Pertama, centralized merupakan arsitektur TIK yang tersentralisasi. Kedua, integrated, merupakan sistem aplikasi yang terintegrasi dan terpadu. Ketiga, connected, merupakan sistem aplikasi yang terhubung dengan entitas eksternal terkait. Keempat, automated merupakan sistem aplikasi yang sudah full automation.

Kantor Pelayanan Utama Bea dan Cukai Tipe A Tanjung Priok memberikan kesempatan pada berbagai universitas untuk melakukan kunjungan (study tour) dalam memperkenalkan instansi dan proses kerja pada masyarakat, berupa informasi kegiatan ekspor dan impor barang secara langsung. Civitas akademik dinilai sangat berperan dalam penyebaran informasi positif, khususnya di bidang pemerintahan. Salah satu contohnya kegiatan study tour diawali pemaparan materi kepabeanan dan cukai. Lalu para civitas akademik diberikan pengetahuan mengenai Customs Narcotis Team (CNT). Setelah itu, rombongan diajak berkeliling pelabuhan Tanjung Priok untuk melihat fasilitas Hico Scan X Ray Bea Cukai.

Selain study tour, Kantor Pelayanan Utama Bea dan Cukai Tipe A Tanjung Priok mengadakan kegiatan penyuluhan kepada pengguna jasa atau instansi terkait melalui bidang Bimbingan Kepatuhan dan Layanan Informasi (BKLI) mengenai peraturan baru terkait kegiatan ekspor atau impor barang. Siswa/siswi atau mahasiswa yang sedang Praktik Kerja Lapangan (PKL) atau magang dapat membantu kegiatan penyuluhan ini. Satu contoh kegiatannya ialah sosialisasi Peraturan Kementerian Keuangan Republik Indonesia No. 229/PMK.04/2017 tentang tata cara pengenaan tarif bea masuk atas barang impor berdasarkan perjanjian atau kesepakatan internasional resmi berlaku. Kantor Pelayanan Utama Bea dan Cukai Tipe A Tanjung Priok mengadakan sosialisasi kepada perusahaan non MITA/AEO untuk memberikan pemahaman yang lebih baik.

Proses disseminating mengenai dokumen impor harus diteliti lebih dahulu oleh PFPD melalui sistem CEISA, yang sudah tertera data lengkap untuk proses pemeriksaan dokumen impor. PFPD memeriksa dokumen impor setelah diberikan persetujuan pengeluaran barang, dan ditetapkan dokumen tersebut masuk ke dalam dokumen jalur hijau. Adapun PFPD yang telah menetapkan dokumen impor menjadi dokumen yang jalur merah dan jalur kuning, lalu melakukan penyebaran informasi kepada importir berupa penerbitan surat 
pemberitahuan, surat penetapan atau nota pemberitahuan.

Hal ini contohnya terjadi pada barang impor mewah, seperti barang elektronik atau kendaraan mewah. Importir diberikan waktu mengurus perizinan agar barang tersebut dapat legal, dengan waktu 3 bulan. Namun, apabila importir tidak mengurus perizinan, maka Kementerian Keuangan akan menetapkan barang tersebut menjadi barang milik negara. Setelah status barang menjadi barang milik negara, barang tersebut akan dilelang dan hasilnya akan masuk ke dalam kas negara. Kemudian untuk barang terlarang seperti narkotika dan sejenisnya, akan langsung dimusnahkan. Selain itu, barang impor yang dikemas untuk penjualan eceran, pengeluaran dari kawasan pabean atau tempat lain di bawah pengawasan pabean hanya dapat dilakukan setelah dilekati tanda lunas atau pengawasan cukai sesuai ketentuan berlaku.

Dokumen barang impor yang telah selesai diperiksa, akan dikirimkan PFPD kepada kepala seksi pabean dan cukai. Pada hasil cetak SPPB dicantumkan keterangan bahwa formulir ini dicetak secara otomatis oleh sistem komputer dan tidak memerlukan nama, tanda tangan pejabat, dan cap dinas. Importir menerima dokumen tersebut secara elektronik pada portal pabean yang tersedia melalui CEISA dan mencetak dokumennya. Setelah importir mencetak SPPB, lalu dokumen ini diserahkan SPPB kepada pejabat yang mengawasi pengeluaran barang dari kawasan pabean atau TPS oleh importir. Kemudian importir menerima SPPB yang diberikan catatan oleh Pejabat yang mengawasi pengeluaran barang. Tahap akhir adalah importir mengeluarkan barang impor dari kawasan pabean.

\section{SIMPULAN}

Pada proses pengelolaan arsip dinamis dokumen impor barang di Kantor Pelayanan Utama Bea dan Cukai Tipe A Tanjung Priok dilakukan melalui 3 (tiga) tahapan di antaranya: proses recording, proses organization, dan proses dissemination. Pada proses recording, pengelolaan arsip dokumen pemberitahuan impor barang sudah sesuai prosedur, melalui tahapan proses penciptaan dan penerimaan dokumen pemberitahuan impor barang. Dokumen Pemberitahuan Impor Barang (PIB) dibuat importir berdasarkan dokumen pelengkap pabean dan dokumen pemesanan pita cukai dengan menghitung sendiri bea masuk, cukai, dan Pajak Dalam Rangka Impor (PDRI) yang seharusnya dibayar. Dokumen pemberitahuan impor barang yang diterima akan dilakukan pemeriksaan melalui 3 (tiga) tahapan, yaitu pemeriksaan kelengkapan dokumen, perekaman data pada aplikasi SIAP, serta pemeriksaan mengenai kelengkapan dokumen kepabeanan. Proses organization dalam pengelolaan arsip dokumen pemberitahuan impor barang melalui pendistribusian dokumen dari Bagian Penerimaan Dokumen ke PFPD, proses penyelesaian administrasi kepabeanan dokumen impor oleh PFPD, penyimpanan dokumen yang telah selesai diproses, penemuan kembali dokumen hingga pemeliharaan dokumen. Proses dissemination dilakukan melalui penyebaran informasi mengenai dokumen impor yang sudah diproses oleh PFPD kepada importir. PFPD memiliki wewenang melakukan penyebaran informasi kepada importir berupa 
penerbitan surat pemberitahuan, surat penetapan atau nota pemberitahuan yang disampaikan pada pihak importir. Proses selanjutnya yang dilakukan Kantor Pelayanan Utama Bea dan Cukai Tipe A Tanjung Priok untuk mengurangi dwelling time dengan mempertahankan kinerja para pegawai dalam melayani proses administrasi dokumen impor berupa kecepatan dalam penyelesaian dokumen dan kesigapan dalam memeriksa barang impor melalui ketelitian tinggi. Pengelolaan arsip dinamis dokumen impor barang di Kantor Pelayanan Utama Bea dan Cukai Tipe A Tanjung Priok merupakan penelitian menarik. Bagaimana dokumen yang dihasilkan menjadi ciri khas lembaga tersebut. Untuk itu, penelitian mengenai pengelolaan arsip dinamis perlu dikembangkan lagi, misalnya akan diteliti ke instansi lain di pemerintahan Indonesia. Hal ini untuk melihat proses pengelolaan arsip dari latar belakang instansi yang berbeda.

\section{DAFTAR PUSTAKA}

Chairisnaeni, W., Rusmana, A., \& Komariah, N. (2014). Pengelolaan dokumen Inspektorat Pembantu Kota Administrasi Jakarta Selatan. Kajian Informasi \& Perpustakaan, 2(1), 57-64. https://doi.org/10.24198/jkip.v2i1.11 634

Darono, A., Nugroho, L. E., \& Najib, W. (2013). Tinjauan interpretatif terhadap aspek-aspek institusional dalam implementasi layanan elektronik: Studi kasus PT. xyz. JNTETI: Jurnal Nasional Teknik Elektro Dan Teknologi Informasi, 2(1), 29-36. https://doi.org/10.22146/jnteti.v2i1.2 5

Direktorat Jenderal Bea dan Cukai KPU Bea dan Cukai Tipe A Tanjung Priok.
(2019). Tugas pokok dan fungsi. Retrieved from http:/ / bcpriok.beacukai.go.id/ website:

http:/ / bcpriok.beacukai.go.id/?2d08 2f81b77428658774368d7fa57165

Kantor Pelayanan Utama Bea dan Cukai Tipe A Tanjung Priok. (2018). Aplikasi SIAP. Jakarta: Kantor Pelayanan Utama Bea dan Cukai Tipe A Tanjung Priok.

Kusnandar, \& Yusup, P. M. (2015). Pengembangan modul public users pada sistem informasi kearsipan akademik elektronik (SIAMEL). Kajian Informasi $\mathcal{E}$ Perpustakaan, 3(1), 1-8. https://doi.org/10.24198/jkip.v3i1.93 51

Nugrohoadhi, A. (2015). Pengorganisasian dokumen dalam kegiatan kepustakawanan. Khizanah Al-Hikmah: Jurnal Ilmu Perpustakaan, Informasi, Dan Kearsipan, 3(1), 1-10. https:/ / doi.org/10.24252/kah.v3i1a1

Nurrahman, A. (2016). Pengelolaan arsip dinamis aktif di bagian Kearsipan Sekretariat Jenderal Dewan Perwakilan Daerah Republik Indonesia untuk menunjang kegiatan administrasi (Skripsi). Universitas Padjadjaran, Sumedang.

Nurulita, A. (2015). Sistem pengelolaan arsip dinamis pada administrasi perkantoran di Biro Umum Sekretariat Jenderal Kementrian Pekerjaan Umum Republik Indonesia (Skripsi) (Universitas Islam Negeri Syarif Hidayatullah). Retrieved from http:/ / repository.uinjkt.ac.id/dspace /bitstream/123456789/29400/1/AN NISA NURULITA-FAH.pdf

Ramadhani, D. A., \& Subekti, S. (2018). Pengelolaan arsip statis dalam mendukung pelayanan informasi di 
Dinas Kearsipan dan Perpustakaan

Retrieved from

Provinsi. Jurnal Ilmu Perpustakaan, http:/ /ojs.stiami.ac.id/index.php/JUPASI 7(4), 171-180. Retrieved from / article/view/506/317 https:// ejournal3.undip.ac.id/index. php/jip/article/view/22960/20997 Wardiana, D., Khadijah, U. L. S., \& Rukmana, E. N. (2018). Dokumentasi budaya ngaruat lembur di Radio RASI FM. Kajian Informasi $\mathcal{E}$ Perpustakaan, 6(1), 43-58. https://doi.org/10.24198/jkip.v6i1.15 325

Jurnal Pajak Vokasi, 1(1), 57-69. 


\section{DAFTAR TABEL}

Tabel 1

Temuan penelitian

\begin{tabular}{|c|c|c|}
\hline No. & $\begin{array}{l}\text { Pertanyaan } \\
\text { penelitian }\end{array}$ & Temuan penelitian \\
\hline 1 & Proses recording & $\begin{array}{l}\text { - Penciptaan sumber dokumen dari para importir, } \\
\text { yang dilakukan bagian penerimaan dokumen } \\
\text { Penerimaan dan pemeriksaan melalui tahap } \\
\text { pemeriksaan kelengkapan dokumen, perekaman } \\
\text { data, dan pemeriksaan mendalam. }\end{array}$ \\
\hline 2 & $\begin{array}{l}\text { Proses } \\
\text { organization }\end{array}$ & $\begin{array}{l}\text {-Pendistribusian dokumen } \\
\text {-Penyelesaian administrasi } \\
\text { - Penyimpanan dokumen } \\
\text {-Penemuan kembali dokumen } \\
\text {-Perawatan dokumen }\end{array}$ \\
\hline 3 & $\begin{array}{l}\text { Proses } \\
\text { dissemination }\end{array}$ & -Menggunakan sistem CEISA \\
\hline
\end{tabular}

Sumber: Hasil penelitian, 2018 


\section{DAFTAR GAMBAR}

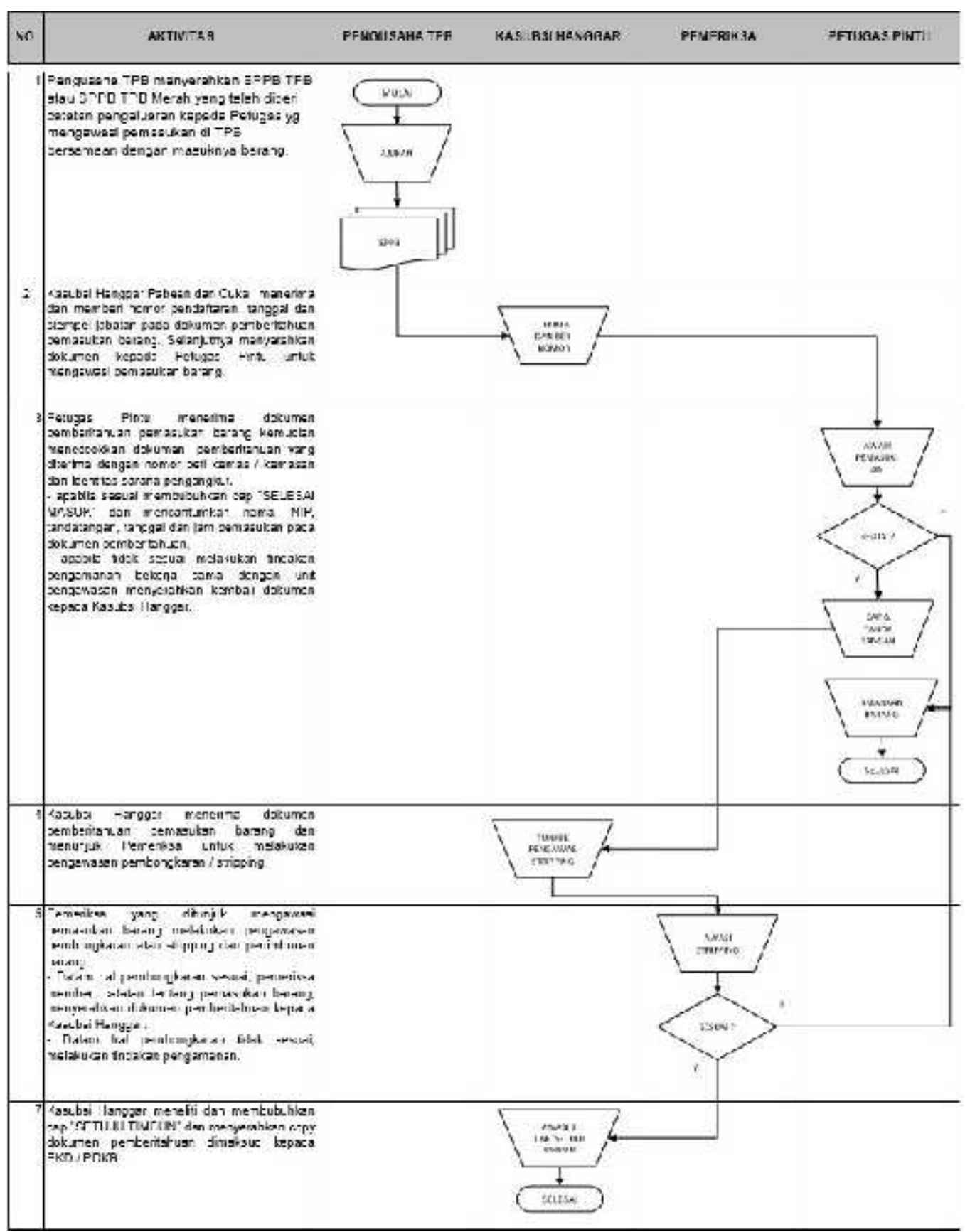

Gambar 2. Standar prosedur operasi bagian penerimaan dokumen

Sumber: Kantor Pelayanan Utama Bea dan Cukai Tipe A Tanjung Priok, 2018 


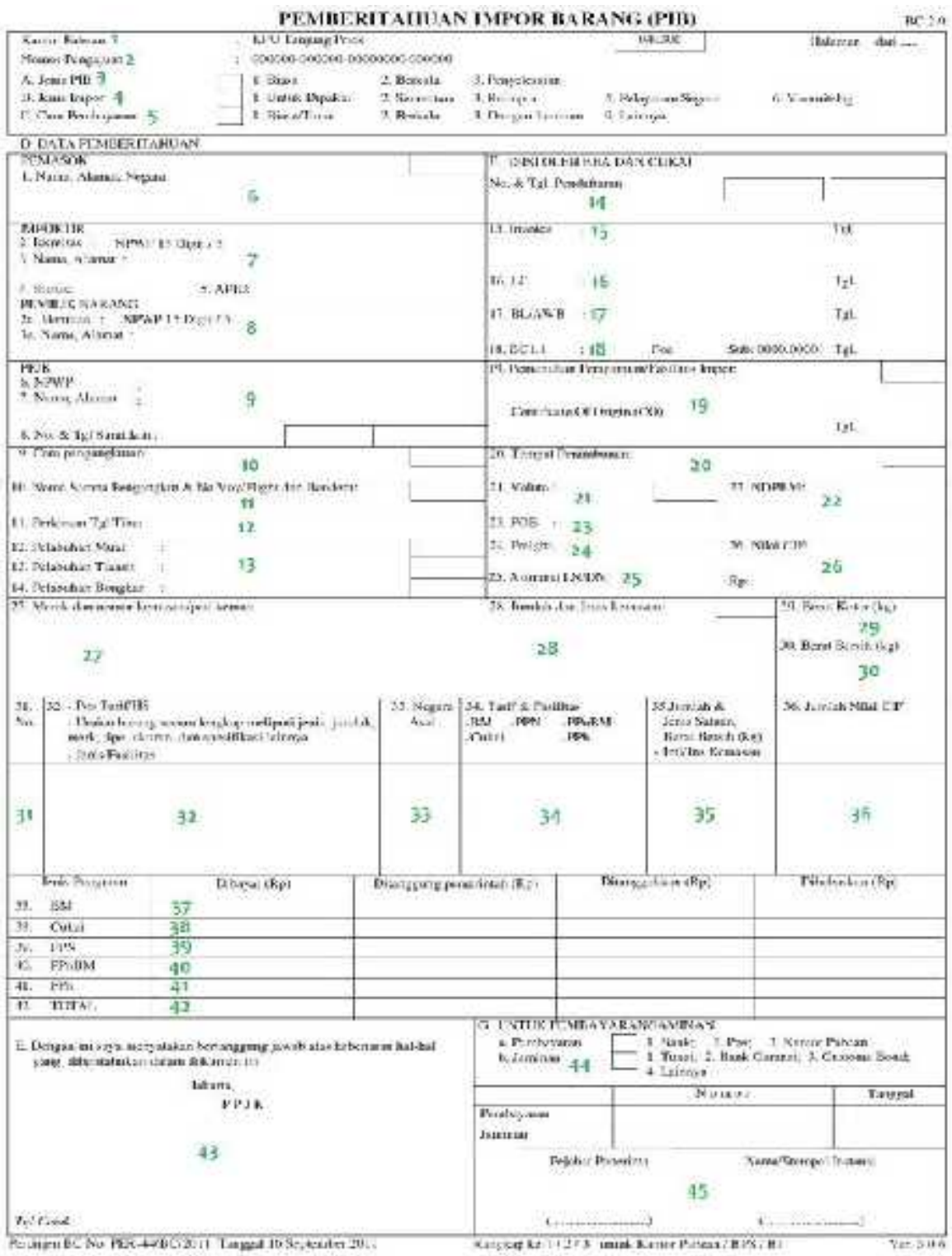

Gambar 3. Contoh dokumen Pemberitahuan Impor Barang (PIB) Sumber: Kantor Pelayanan Utama Bea dan Cukai Tipe A Tanjung Priok, 2018 